\title{
JAUES
}

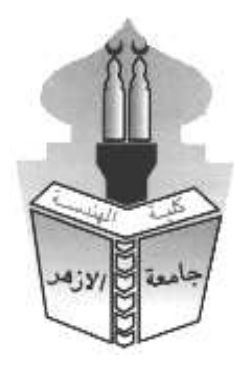

\section{EFFECT OF AXIS RATIO ON HEAT TRANSFER FROM AN ELLIPTIC CYLINDER IMMERSED IN A FLUIDIZED BED}

\author{
M. A. Mohammad \\ Mechanical Engineering Department, Faculty of Engineering, Al-Azhar University, Cairo, Egypt \\ *Corresponding Author's E-mail: mostafa_azhar2015@yahoo.com
}

Received: 29 April $2021 \quad$ Accepted: 08 June 2021

\begin{abstract}
Heat transfer characteristics around three elliptical cylinders with different axis ratio in a fluidized bed are experimentally studied. Air is used to fluidise 3 batches of different sizes of silica sand, of 500, 780 and $950 \mu \mathrm{m}$ average diameter. The cylinder axes ratio AR (longitudinal axis / transverse axis) for the experimented cylinders are 1, 2, and 4. Behaviours of local Nusselt numbers as a function of cylinder's axis ratio around the tube surface are presented. The impact of Reynolds number, average particles size and cylinder's axis ratio on average Nusselt number are demonstrated. The results showed that for all cases the average rate of heat transfer improves with Reynolds number. For the same average particle size of the bed, the average rate of heat transfer improves with increasing axis ratios. The results also showed that for the same axis ratio, the average rate of heat transfer decreases with increasing the mean particles size. The experimental results of a cylinder with axis ratio= 1 is compared with another work and a good agreement is noticed
\end{abstract}

KEYWORDS: Heat transfer, Fluidized bed, Elliptical tube, Axis ratio.

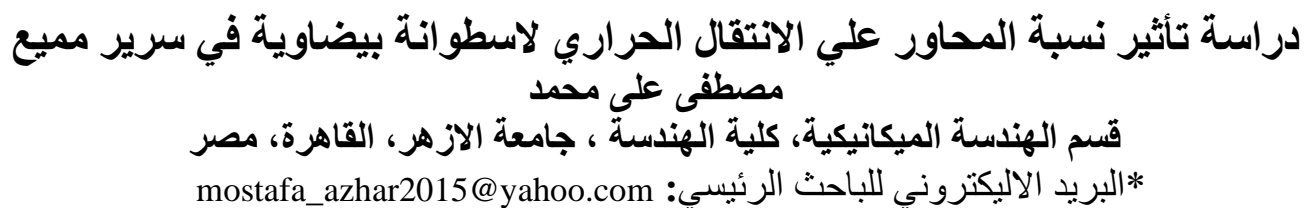

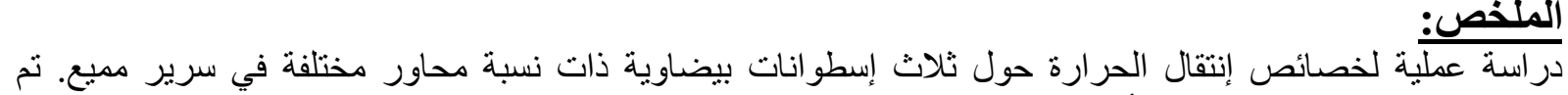

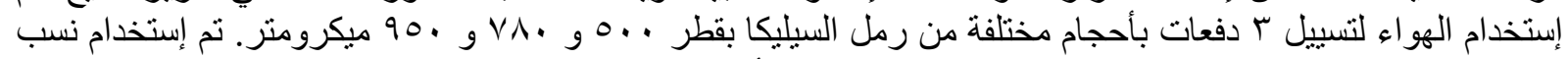

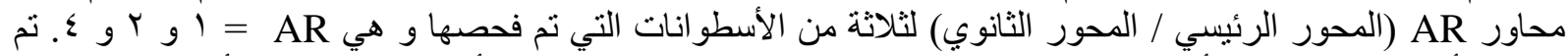

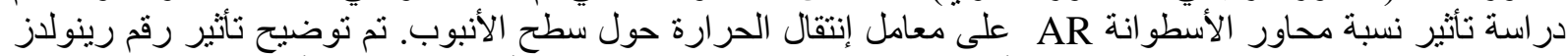

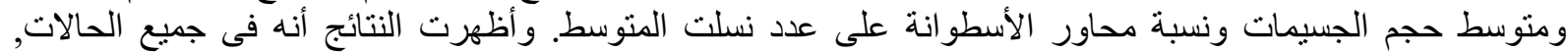

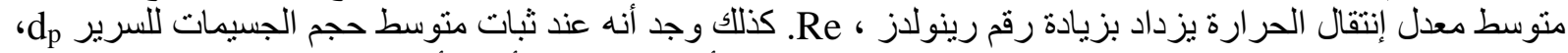

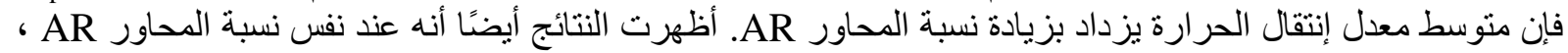

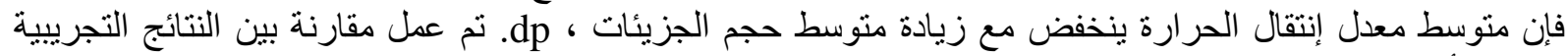

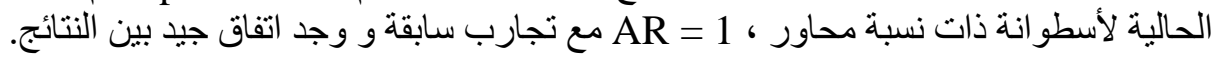




\section{INTRODUCTION}

Fluidized beds are found promising for "clean wastes technology" such as applications in electric power generation, because of their efficient and clean burning of coal which reduced pollutants [1]. Heat exchangers are used in the fluidization process to remove/add heat to the fluidized bed by cooling or heating coils. Heat exchangers are mainly depending on cylinders as standard immersion elements that can exchange heat. To enhance the heat transfer, a surface geometry that provides high heat transfer rates with the lowest pressure drop is definitely preferred because of reducing the consumed power. As a result, it is useful to determine the evaluation standards that can be advanced to obtain the performance of the heat exchangers based on the enhancing of the heat transfer and decreasing the cost of the consumed power.

Numerous attempts have been made for studying the heat transfer and fluid flow characteristics around "enhanced heat transfer surface" of different cross-sectional shapes. An array of tubes is one of the famous and simplest arrangements which is used widely for heat transferrapplications. A great deal of effort has been expended on the acquisition and correlation of experimental data for the circular cylinder, and a sequence of developed algebraic representations for the heat transfer characteristics has been incoming [2-7].

furthermore, for non circular cylinders (semi-circular, square, rectangular, diamond, triangle and ......etc), relatively available information exists [8-24]. Such device has to be consolidated, light-weight and of high performance. Using of streamlined cylinders is usually used because of the relative ease of fabrication as well as the wake region behind the cylinder and drag coefficient are small when compared to a circular one. Crossflow heat exchanger with elliptic tube arrangement is receiving increased attention, because it produces enhancing heat transfer compared with the other tube cross-section [25-29]. Raman et al. [30] simulated flow past unconfined elliptic cylinder with various axis ratios (AR) of $0.1,0.2,0.3,0.4,0.5$, $0.6,0.7,0.8,0.9$ and 1, to predict fluid flow characteristics at Reynolds number $\operatorname{Re}=50$ and $\operatorname{Re}=100$. The wake sizes behind the cylinder and the coefficient of drag are noticed to enhances with increasing AR but decrease with increase in Reynolds number. Li et al. [31] studied the coefficients of heat transfer and drag over the outer surface of tubes have elliptical cross section with minor/major axes ratio of $0.3,0.5$, and 0.8 for Reynolds numbers ranged from 500 to 10,000 . It is found that an elliptical cylinder with an axes ratio equal to 0.5 causes pressure drop by $30 \%$ to $40 \%$ comparing with that of a circular cylinder. Nusselt number of lenticular or elliptical cylinder with axes ratio of 0.5 and 0.3 is about 17 to $35 \%$ lower than that of a circular cylinder. Terukazu et al. [32] found that for elliptical tube, drag coefficient and pressure drop is lower than that of a circular cylinder so the elliptical tube performs better than the circular configuration. Badr [33] studied numerically the effects of axes ratio and the angle of attack on heat transfer coefficient for isothermal surface of a single cylinder with elliptical cross section. Reynolds number is ranged from 20 to 500. It is found that the maximum convective heat transfer occurs at zero angle of attack. Blaszczuk et al. [34] studied experimentally the effect of the mean size of bed particle, density, and fluidizing number on the heat transfer characteristics in a fluidized bed with an array of submerged super heater tubes. It is concluded that the heat transfer coefficient increases with the decreases of the size of bed particle. Furthermore, because of the reduction of the solids mixing and the increasing emulsion contact time on the tube surface, it is noticed that the heat transfer coefficient decreases. Kim and Kim [35] and Olsson and Almstedt [36] studied the influence of pressure and fluidization velocity on heat transfer coefficients between a horizontal tube submerged in a fluidized bed with silica sand particles. Because of pressure increasing due to the increase of density it is noticed a significant increase in average heat transfer coefficient. Bansal [37], Masoumifard et al. [38], Burr [39], Baskakov and Berg [40] investigated experimentally the effects of fluidization velocity and particle size/ type on fluid flow and heat transfer 
mechanisms associated with the tube bundle in a gas fluidized bed. He observed that at flow rates in the range of incipient fluidization, the onset of fluidization occurs at the tube sides, with a corresponding increase in local heat transfer coefficient in that region. Nagahashi [41] investigated the dynamic forces on submerged tubes fixed horizontally with different crosssection area, both singly and in arrays of such tubes, in a fluidized bed.

As summarized through the above survey and up to the authors' knowledge, it can be noticed that some researchers investigated the effect of some parameters like fluidizing velocity and mean particle diameter on the average heat transfer coefficient between the fluidizing bed and immersed heating element. Otherwise, it is noticed that less literatures available on the effect of elliptic tube axes ratio on the convective coefficient of heat transfer around the horizontal tube and the fluidized bed. So, the main objective of this work is to study the effect of tube axes ratio on the heat transfer coefficient around a horizontal elliptical tube immersed on fluidized bed.

\section{EXPERIMENTAL WORK}

The same setup was used in a previous work on the heat transfer from elliptic tube to fluidized bed of Coal [42]. A test rig is constructed to measure the heat transfer characteristics from the elliptical tested cylinder which is immersed in a fluidized bed. The test rig includes a test section, fluidizing system, wind tunnel, and measuring instruments. Fig. 1 shows the basic components of the test rig.

Centrifugal plower with AC motor.
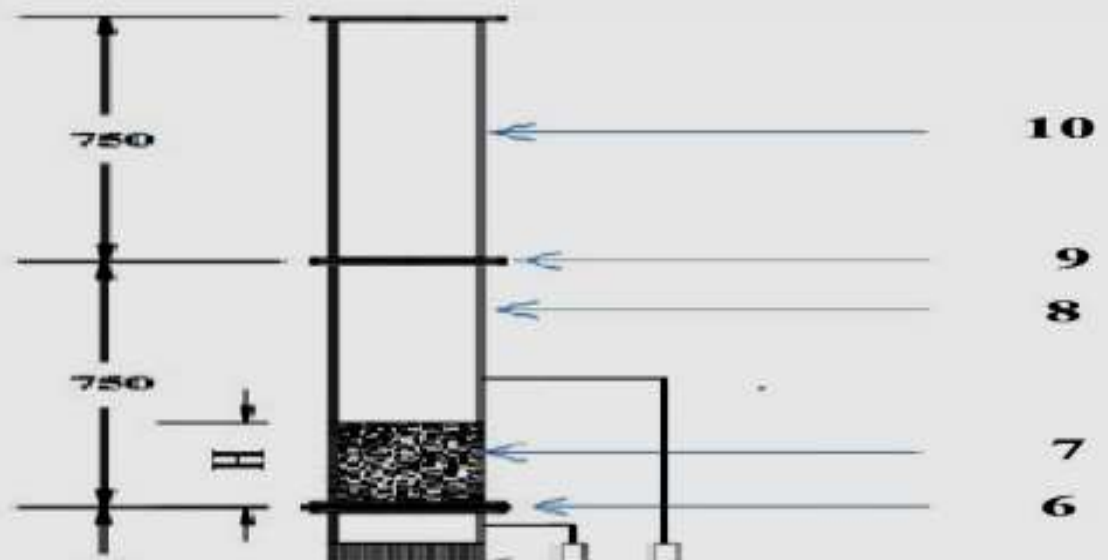

Ball control valve.

Pitot tube with manometer.

: Plenum with honey comb.

: U-tube manometer

Distributor plate.

: Bed material \& heat exchanger

8 : Bed chamber.

Figure 1: The experimental set-up

9 : Flanges with rubber.

10 : Freeboard region 
An open loop wind tunnel is constructed to give air velocity with uniform distribution through the test section. The test section wall is made of acrylic glass material to enable visual observations of the fluidized bed behavior. And, it is kept vertically and has a length of 1000 $\mathrm{mm}$ while its outlet and inlet cross section are square, with dimensions of $200 \mathrm{~mm} \times 200 \mathrm{~mm}$. Air is forced through the test section and the wind tunnel by a centrifugal blower. To control the air flow rate through the test section a ball control and bypass valves are used. Standard Pitot tube with a liquid manometer is used to measure the air velocity before entering the test section. The fluidizing air with superficial velocities from 0.2 to $0.45 \mathrm{~m} / \mathrm{s}$ enters the test section from the bottom through the distributor plate. Heat transfer takes place in the test section from the tested cylinder to the fluidized bed by using a cartridge heater of outer diameter of $16 \mathrm{~mm}$ and net length of $200 \mathrm{~mm}$. The test section is filled with silica sand up to a static height of $\mathrm{H}=150 \mathrm{~mm}$ while the tested cylinder is located horizontally crosses the bed region far from the middle of the $100 \mathrm{~mm}$ side as shown in Fig. 2.

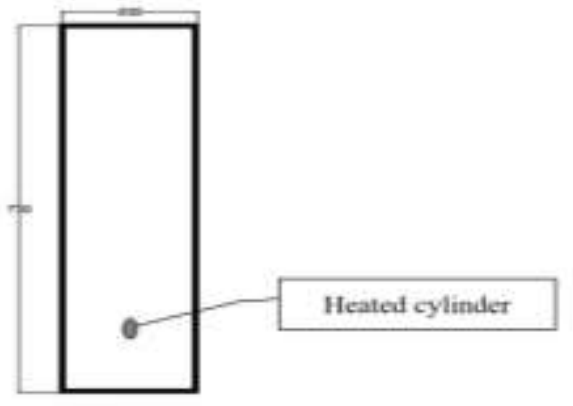

Figure 2: Cylinder position.

The tested cylinders are made of polished cupper and ended with two wooden tips to minimize axial heat loss; their dimensions are given in Table 1.

Table 1: Shapes and dimensions of the tested elliptical cylinders

\begin{tabular}{ccccc}
\hline Specimens & Major length, $\mathbf{a}$ & Minor length, $\mathbf{b}$ & Hydraulic diameter, $\mathbf{D}_{\mathbf{h}}$ & Axis ratio, $\mathbf{a} / \mathbf{b}$ \\
\hline Case 1 & 40 & 10 & 29.3 & 4 \\
Case 2 & 35.4 & 17.7 & 45.9 & 2 \\
Case 3 & 27.3 & 27.3 & 54.6 & 1 \\
\hline
\end{tabular}

Eight thermocouples of $0.5 \mathrm{~mm}$ diameter copper-constantan (T-type) is fitted to measure the temperature at points on the outer surface of the test cylinder. The thermocouples are placed in equidistance on the circumference of the tested cylinder at the middle at $45^{0}$ intervals $(100$ $\mathrm{mm}$ from both inside test section walls) as shown in Fig. 3 .
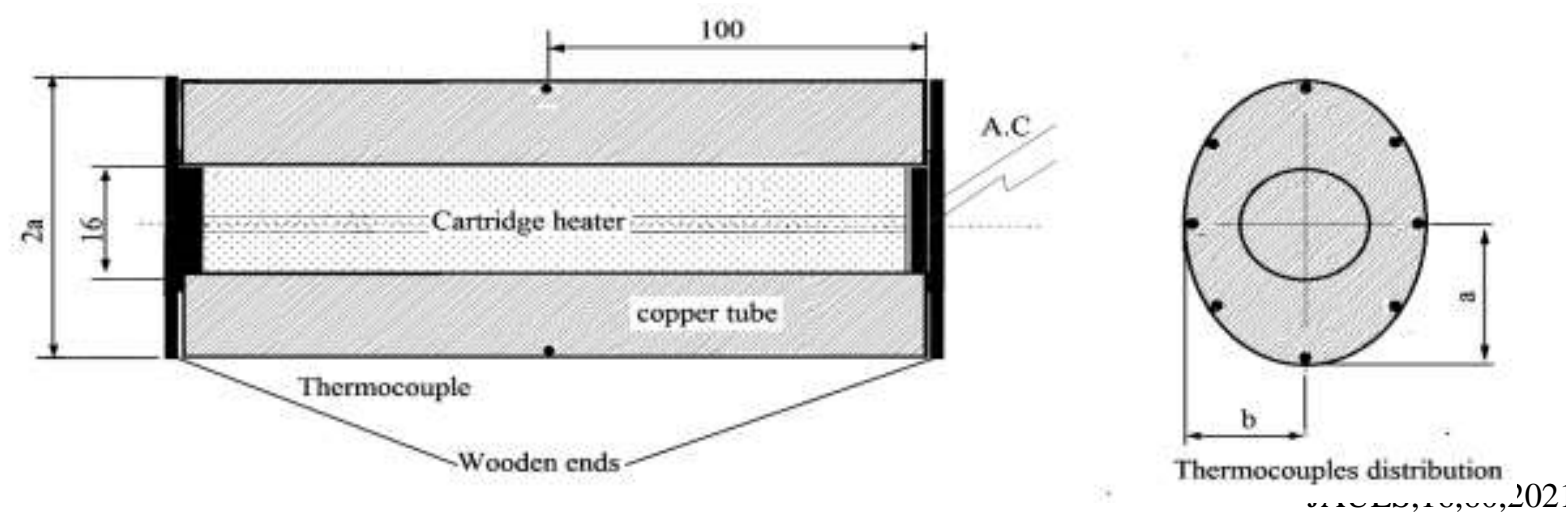
Figure 3: Details of the tested cylinder

To determine the average wall temperature, the thermocouples are imbedded into notches and grooves along the test cylinder. Groove's length is nearly $100 \mathrm{~mm}$ with width of $5 \mathrm{~mm}$ and depth of $0.8 \mathrm{~mm}$ from the outer surface of the test cylinder. The thermocouples wires and junctions are fixed by plastic steel epoxy (devcon) and the free wire terminals are connected via 12-channel selector switch to the temperature recorder. Also, there are two thermocouples of the same type are mounted at the middle of the bed region before and after the tested cylinder to measure mean bed temperatures. Experiments are conducted in a laboratory fluidized bed heat exchanger with silica sand of average diameters of $500 \mu \mathrm{m}, 780 \mu \mathrm{m}$ and $950 \mu \mathrm{m}$. Air and material properties are listed in Table 2. The pressure drop across the bed is measured by using U-tube manometer, through holes on the sidewall of the test section. Various values of Reynolds number, $\mathrm{Re}$, are based on the hydraulic diameter of the heated cylinders and are ranged from 690 to 1550 . The experimental data are based on the equivalent hydraulic diameter, $\mathrm{D}_{\mathrm{h}}$, of the tested heated cylinder which can be calculated as follows:

$$
D_{h}=\frac{4 A_{C}}{P}
$$

Where Ac is the cross section area, and $\mathrm{P}$ is perimeter of the heated tube.

- The local heat transfer coefficients are computed using the equation.

$$
h_{\theta}=\frac{V I}{A_{s}\left(T_{s, \theta}-T_{b}\right)}
$$

Where $\mathrm{I}$ and $\mathrm{V}$ are the current and the voltage of the cartridge heater while As, Ts, $\theta$ and $\mathrm{T}_{\mathrm{b}}$ are the tested cylinder surface area, local surface and mean bed temperatures, respectively.

Therefore, the local Nusselt numbers are calculated by:

$$
N u_{\theta}=\frac{h_{\theta} D_{h}}{K_{a}}
$$

- By integrating the local values of $\mathrm{Nu}_{\theta}$ over the entire perimeter of the tested cylinder, the average Nusselt number, $\mathrm{Nu}$, is calculated as:

$$
N u=\int_{-\pi}^{\pi} N u_{\theta} d_{\theta} / 2 \pi
$$

- Reynolds number based on the hydraulic cylinder diameter, Re, is calculated as follows:

$$
\operatorname{Re}=\frac{\rho_{a} U_{\infty} D_{h}}{\mu_{a}}
$$

- Archimedes number is given by

\subsection{Measurements' Uncertainties}

$$
A r=\frac{g \rho_{g}\left(\rho_{s}-\rho_{g}\right) d_{p}^{3}}{\mu_{g}^{2}}
$$

The error analysis of the experimental work shows the inclusion of the measured parameters error on the results uncertainty. A differential analysis for the experimental uncertainties is carried out using error analysis differential approximation method [43]. The maximum uncertainties in measuring the investigated parameters are $0.5 \%$ for air temperature, $3.1 \%$ for air velocity before the test section, and $2.17 \%$ for pressure drop across the bed.

- The properties of the fluidizing gas, air, are evaluated at mean film temperature, $\mathrm{T}_{\mathrm{mf}}$ and listed in Table 2. 
Table 2: Properties of phases used in the present study [44]

\begin{tabular}{cccc}
\hline Parameters & Value & Parameters & Value \\
\hline$\rho_{\mathrm{a}}\left(\mathrm{kg} / \mathrm{m}^{3}\right)$ & 1.071 & $\mathrm{~d}_{\mathrm{p}}(\mu \mathrm{m})$ & 500,780 and 950 \\
$\mu_{\mathrm{a}}(\mathrm{kg} / \mathrm{m} . \mathrm{s})$ & $1.991 * 10^{-5}$ & $\rho_{\mathrm{p}}\left(\mathrm{kg} / \mathrm{m}^{3}\right)$ & 2600 \\
$\mathrm{C}_{\mathrm{Pa}}(\mathrm{J} / \mathrm{kg} . \mathrm{K})$ & 1007 & $\varepsilon_{\mathrm{s}}$ & 0.58 \\
$\mathrm{k}_{\mathrm{a}}(\mathrm{W} / \mathrm{m} . \mathrm{K})$ & 0.02781 & $\mathrm{H}_{\mathrm{st}}(\mathrm{m})$ & $0.15 \mathrm{~m}$ \\
$\mathrm{P}_{\mathrm{r}}$ & 0.721 & & \\
\hline
\end{tabular}

\section{RESULTS AND DISCUSSION}

\subsection{Minimum fluidization velocity}

The relation between the pressure drop across the bed and superficial velocity, $\Delta \mathrm{P}-\mathrm{Usup}$, is very important to estimate the minimum fluidization velocity, Umf, as it is located at the point when the superficial velocity is increased and pressure drop becomes constant. The experimental values of $\Delta \mathrm{P}$ and $\mathrm{Umf}$ are linked closely with mean particles as illustrated in Table 3.

Table 3: Experimental values of pressure drop and minimum fluidization velocity

\begin{tabular}{lccc}
\hline Particle size & $\Delta \operatorname{Pmf}($ Pascal $)$ & $\operatorname{Umf}(\mathrm{m} / \mathrm{s})$ & $\operatorname{Ar}(-)$ \\
\hline $\mathrm{dp}=500 \mu \mathrm{m}$ & 2115 & 0.2 & 10593 \\
$\mathrm{dp}=780 \mu \mathrm{m}$ & 2956 & 0.22 & 40216 \\
$\mathrm{dp}=950 \mu \mathrm{m}$ & 3548 & 0.25 & 72658 \\
\hline
\end{tabular}

From these results, it can be concluded that the minimum fluidization velocity is increased with increasing particle size. Also, it is found that changing the cylinder axis ratio has unremarkable effect on the pressure drop or minimum fluidization velocity.

In this work, different aspect ratios and particle sizes are plotted through the figures to find the pressure drop across the bed and the superficial velocity at the minimum fluidization velocities ( $\triangle \mathrm{Pmf}$ and Umf, respectively), and also the results are shown in Table 3.

\subsection{Effect of Axis Ratio on Heat Transfer}

Firstly, the local Nusselt numbers distributions around three elliptical cylinders immersed in silica sand of $500 \mu \mathrm{m}$ mean diameter for different $\theta$ are presented in Figure 4.

In this Figure, the local heat transfer of the particle flow around heated cylinders, circular cylinder $(\mathrm{AR}=1)$ and elliptical cylinders $(\mathrm{AR}=2$ and 4$)$ are compared. The circumference of circular cylinder cross section is the same as that of elliptical cylinders. Therefore, when the major and minor axes lengths is changed, the cross-section shape of the elliptical tube changes accordingly. It is found that, the local Nusselt numbers distribution around circular cylinder is not of similar trend to that around elliptical cylinder. The situation in the upstream region and particle contacting situation with cylinder wall in the downstream region are worse. This may be attributed to larger particle stagnation and cavitation zones existed in the upstream and downstream regions respectively [45]. Compared with local Nusselt numbers distribution around elliptical cylinders the cavitation and stagnation zone are relatively small. Also, it is indicated that when AR increasing the particle stagnation zone in the upstream region will 
decrease gradually and the particle cavitation zone in the downstream region will also decrease gradually until disappear. Which indicate that the particle flow situation in the upstream region will improve as AR increase and the particle contacting situation with tube wall in the downstream region will also improve when AR increases, so causes increasing in heat transfer coefficient.

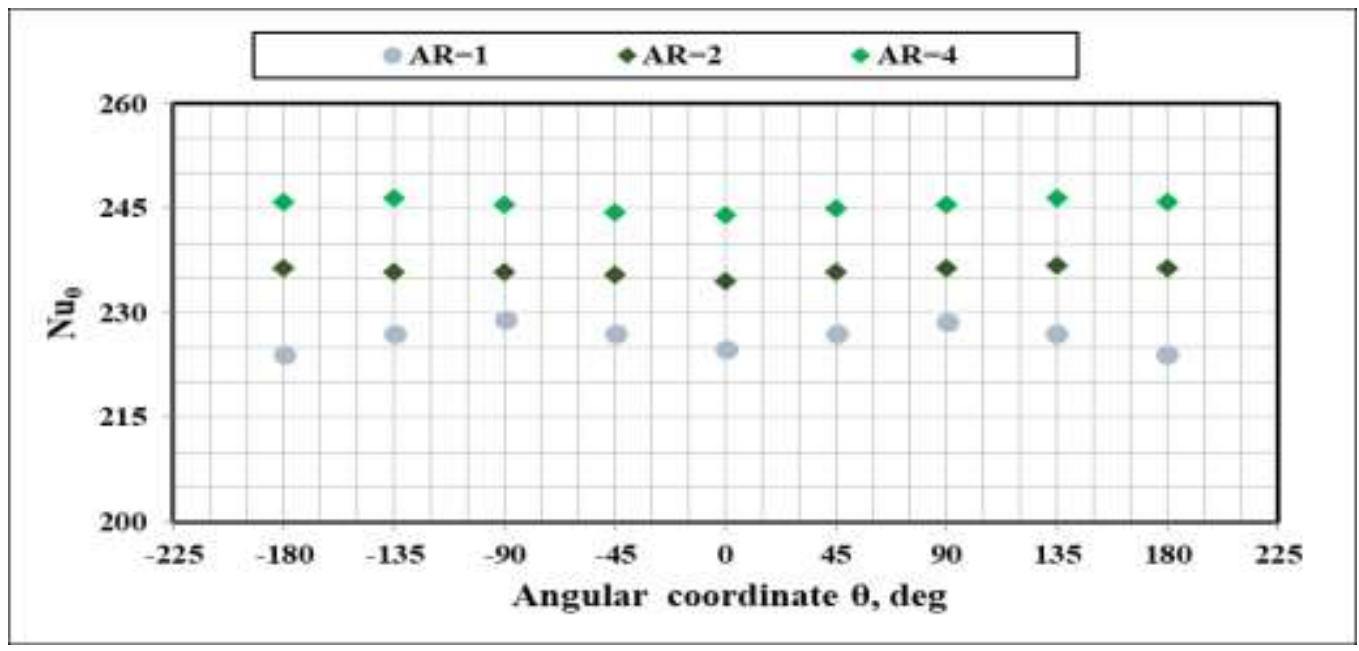

Figure 4: Variation of local Nusselt number, $\mathrm{Nu} \theta$ versus $\theta$ for a single elliptical horizontal cylinder immersed in a bed of $\mathrm{dp}=500 \mu \mathrm{m}$ for different Axis Ratio, AR.

Secondly, the variations of average Nusselt numbers with AR for elliptical cylinders are presented in Figs. 5 through 7. These figures show that, the average Nusselt number, $\mathrm{Nu}$, increases as Reynolds number, Re, increases because of the rapid particle's movement. Also, the results show that $\mathrm{Nu}$ is slightly increased with the increase in axis ratio, AR, of tested cylinder as a result of decreasing motionless regions around cylinder circumferences.

\subsection{The Mean Particle Size Effect on Heat Transfer}

Figs. 8 through 10 show the effect of Reynolds number and particle size on the average Nusselt numbers for a single elliptic cylinder.

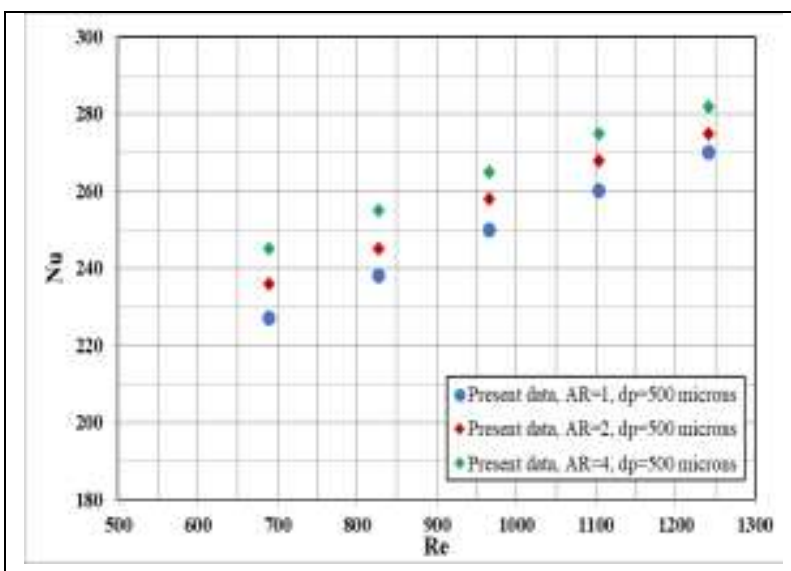

Figure 5: Effect of Axis Ratio, AR, and Reynolds number, Re, on the average Nusselt number, $\mathrm{Nu}$ for single elliptic tube immersed

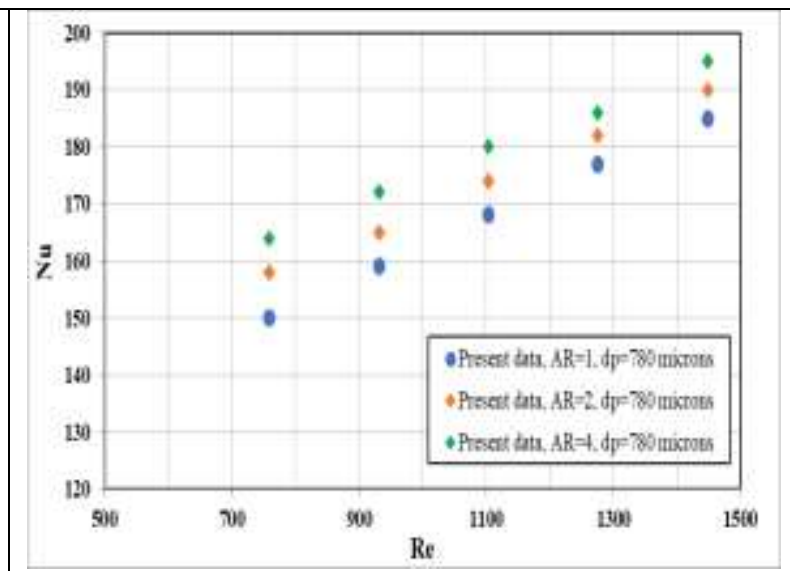

Figure 6: Effect of Axis Ratio, AR, and Reynolds number, Re, on the average Nusselt number, $\mathrm{Nu}$ for single elliptic tube immersed 


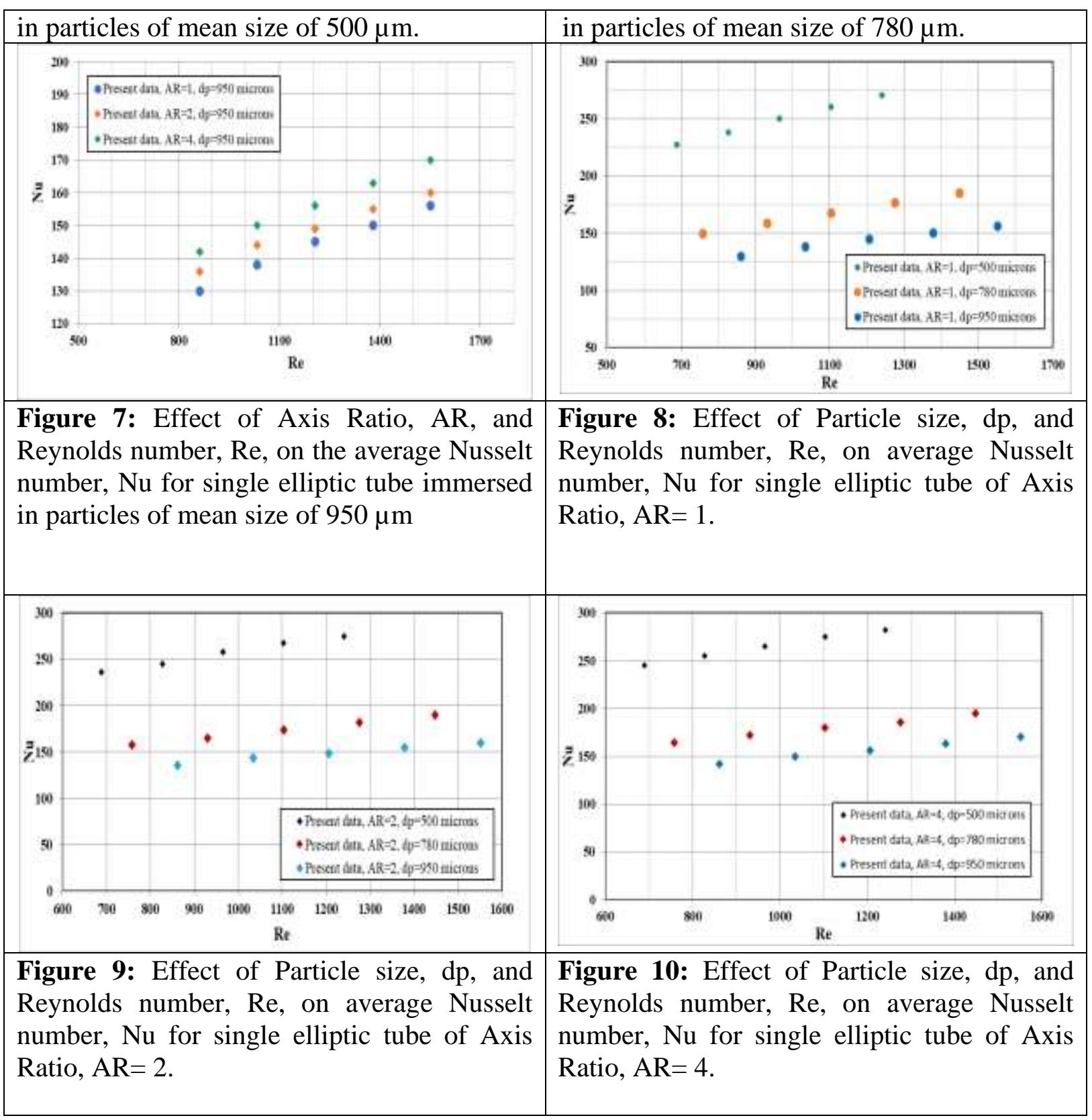

The results show that $\mathrm{Nu}$ decreased with increase in particle size. For certain values of Reynolds number and Axis Ratio, the heat transfer increases as the mean solid particle diameter decreases this is owing to the increase in the effective heat transfer area covered by the particle itself.

\subsection{Comparison with previous work}

There are several correlations and theoretical models available in the literature for the prediction of heat transfer coefficients for circular cylinders immersed in small particle range. The experimental data of the present study of a cylinder of $A R=1$ immersed in different mean particle size, $500 \mu \mathrm{m}, 780 \mu \mathrm{m}$ and $950 \mu \mathrm{m}$ are compared with the calculated values from Eq. 7 of previous study, Bansal [37] as shown in Fig. 11.

$N u=898.2\left(1-\varepsilon_{g}\right)\left(\frac{R e}{A_{r}}\right)^{0.3287} \operatorname{Pr}^{0.3}$

For $\mathrm{Ar} \geq 2550$ 


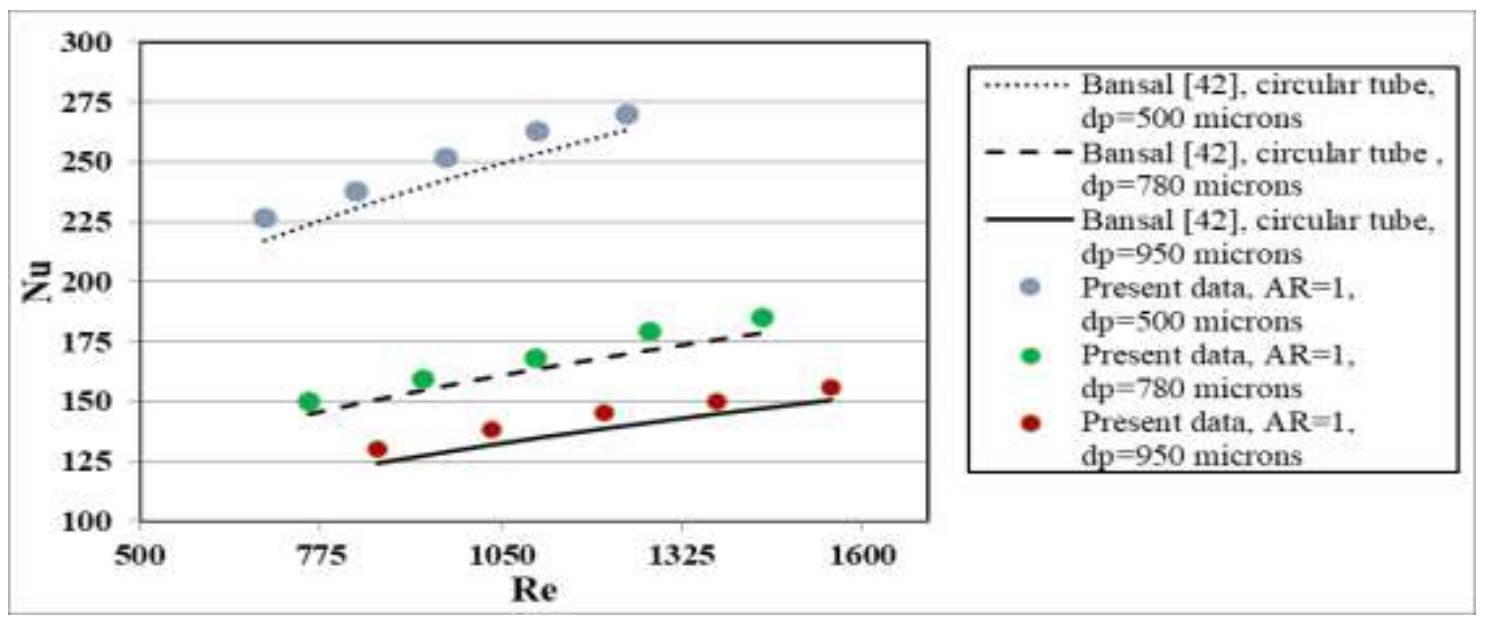

Figure11: Comparison between present work of $\mathrm{Nu}$ for single elliptical tube of $\mathrm{AR}=1$ immersed in particles of mean size of $d p=500 \mu \mathrm{m}$ and circular cylinder that of Bansal [37].

As shown in figure, the experimental Nusselt values of the present study and the predict values which theoretically calculated have the same trends and are slightly higher than that of Bansal [37] for all particle sizes within nearly 5\%.

\section{SUMMARY AND CONCLUSIONS}

The effects of mean particle size, cylinder Axes Ratio, and Reynolds number, on the local and average heat transfer coefficient for a submerged elliptical cylinder in a fluidized bed have been determined. From the present results, it can be concluded that:

1) The pressure drop across the bed and minimum fluidization velocities are increased with the increase in the mean particles size.

2) Increasing AR may be useful to improve the particle flow distributions on both the downstream and upstream regions of the heated cylinder then causes increase for the heat transfer.

3) Reynolds number and particles size have a greater effect than body shape characteristics (Axs ratio).

\section{REFERENCES}

1. H. M. Abdelmotalib, M. A.M. Youssef, A. A. Hassan, S. B. Youn and I. T. Im, "Heat transfer process in gas-solid fluidized bed combustors: A review", International journal of heat and mass transfer, Vol. 89, pp. 567-575, 2015.

2. V. Sharma and A. K. Dhiman, "Heat transfer from a rotating circular cylinder in the steady regime", Thermal Science, Vol. 16, No. 1, pp. 79-91, 2012.

3. B.H. Chang and A.F. Mills, "Effect of aspect ratio on forced convection heat transfer from cylinders", International Journal of Heat and Mass Transfer, Vol. 47, pp. 12891296, 2004.

4. A. Wang and Z. Travnicek, "On the linear heat transfer correlation of a heated circular cylinder in laminar crossflow using a new representative temperature concept", International Journal of Heat and Mass Transfer, Vol. 44, pp. 4635-4647, 2001.

5. W. A. Khan, J. R. Culham and M. M. Yovanovich, "Fluid flow around and heat transfer from an infinite circular cylinder", Journal of Heat Transfer, Vol. 127, pp. 785-790, 2005.

6. K. Abdella and P. S. Nalitolela, "Approximate analytic solutions for forced convection heat transfer from a shear-flow past a rotating cylinder", Applied Mathematical 
Sciences, Vol. 2, No. 11, pp. 497-527, 2008.

7. G. F. Al-Sumaily, J. Sheridan and M. C. Thompson, "Analysis of forced convection heat transfer from a circular cylinder embedded in a porous medium", International Journal of Thermal Sciences, Vol. 51, pp. 121-131, 2012.

8. A. P. S. Bhinder, S. Sarkar and A. Dalal, "Flow over and forced convection heat transfer around a semi-circular cylinder at incidence", International Journal of Heat and Mass Transfer, Vol. 55, pp. 5171-5184, 2012.

9. D. Chatterjee, G. Biswas, and S. Amiroudine, "Numerical investigation of forced convection heat transfer in unsteady flow past a row of square cylinders", International Journal of Heat and Fluid Flow, Vol. 30, No. 1, pp. 1114-1128, 2009.

10. M. Breuer, J. Bernsdorf, T. Zeiser, F. Durst, "Accurate computations of the laminar flow past a square cylinder based on two different methods: lattice-Boltzmann and finite-volume," International Journal of Heat and Fluid Flow, vol. 21, pp. 186-196, 2000

11. S. L. G. Jassim, "Numerical study of the mixed convection flow over a square cylinder", Iraqi Journal of Chemical and Petroleum Engineering, Vol. 11, No. 1, pp. 29-45, 2010.

12. S. Dutta, K. Muralidhar and P.K. Panigrahi "Influence of the orientation of a square cylinder on the wake properties", Experiments in Fluids, vol. 34, pp. 16-23, 2003.

13. J.L. Rosales, A. Ortega, and J.A.C. Humphrey, "A numerical simulation of the convective heat transfer in confined channel flow past square cylinders: comparison of inline and offset tandem pairs", International Journal of Heat and Mass Transfer, vol. 44, pp. 587-603, 2001.

14. B. Paliwal, A Sharma, R.P. Chhabra and V. Eswaran, "Power law fluid flow past a square cylinder: momentum and heat transfer characteristics", Chemical Engineering Science, vol. 58, pp. 5315 -5329, 2003.

15. S.M. Hashemian, M. Rahnama and M. Farhadi, "Turbulent heat transfer in a channel with a built-in square cylinder: the effect of Reynolds number", Scientia Iranica, Vol. 15, No. 1, pp. 57-64, 2008.

16. S. Dutta, P. K. Panigrahi and K. Muralidhar, "Experimental investigation of flow past a square cylinder at an angle of incidence", Journal of Engineering Mechanics, Vol. 134, No. 9, pp. 788-803, 2008.

17. M Ali, O. Zeitoun and A. Nuhait, "Forced convection heat transfer over horizontal triangular cylinder in cross flow", International Journal of Thermal Sciences, Vol. 50, pp. 106-114, 2011.

18. H. Abbassi, S. Turki and S. Ben Nasrallah, "Numerical investigation of forced convection in a plane channel with a built-in triangular prism", International Journal of Thermal Sciences, Vol. 40, pp. 649-658, 2001.

19. M. Rahnama, S. Hashemian and M. Farhadi, "Forced convection heat transfer from a rectangular cylinder: effect of aspect ratio", The 16th International Symposium on Transport Phenomena, Prague, 2005.

20. T. Igarashi, "Fluid flow and heat transfer around rectangular cylinders (the case of a width/height ratio of a section of 0.33-1.5)", International Journal of Heat and Mass Transfer, vol. 30, pp. 893-901, 1987.

21. A. Rokugou, A. Okajima and K. Kamiyama, "Numerical analysis of flow around rectangular cylinders with various side ratios", The 5th Asian Computational Fluid Dynamics, Korea, October, 2003.

22. T. Igarashi, "Characteristics of the flow around rectangular cylinders (the case of the angle of attack 0 degree)", Bulletin of JSME, Vol. 28, No. 242, pp. 1690-1696, 1985.

23. R. W. Davis, E. F. Moore, and L. P. Purtell, "A numerical-experimental study of confined flow around rectangular cylinders", Phys. Fluids, Vol. 27, No. 1, 1984.

24. K. Shimada and T. Ishihara, "Application of a modified K- model to the prediction of aerodynamic characteristics of rectangular cross-section cylinders", Journal of Fluids and Structures, Vol. 16, No. 4, pp. 465-485, 2002.

25. T. Ota, S. Aida, T. Tsuruta, M. Kaga, "Forced convection heat transfer from an elliptic cylinder of axis ratio 1:2," Bulletin JSME, vol. 26, pp. 262-267, 1983.

26. M. S. Mostafa, R. Kamal and M. Gobran, "Flow and heat transfer characteristics around an elliptic cylinder placed in front of a curved plate", Thermal Science, Vol. 
18, No. 2, pp. 465-478, 2014.

27. R. Y. Sakr, N. M. Berbish and A. A. Abd-Aziz, "Influence of free stream turbulence intensity on heat transfer and flow around four in-line elliptic cylinders in cross flow", International Journal of Chemical Reactor Engineering, Vol. 8, pp. 1-28, 2010.

28. W.A. Khan, J. R. Culham and M. M. Yovanovich, "Fluid Flow Around and Heat Transfer from Elliptical Cylinders: Analytical Approach", Journal of Thermophysics and heat transfer, Vol. 19, No. 2, 2005.

29. N. S. Berbish, "Heat transfer and flow behaviour around four staggered elliptic cylinders in cross flow", Heat Mass Transfer, Vol. 47, PP: 287-300, 2011.

30. S. K. Raman, K. A. Prakash and S.Vengadesan "Effect of axis ratio on fluid flow around an elliptic cylinder using immersed boundary method", The 37th National \& 4th International Conference on Fluid Mechanics and Fluid Power, India, 2010.

31. Z. Li, J. Davidson and S. Mantell, "Numerical simulation of flow field and heat transfer of streamlined cylinders in crossflow", ASME Summer Heat Transfer Conference, USA, 2005.

32. O. Terukazu, N. Hideya, T. Yukiyasu, "Heat transfer and flow around an elliptic cylinder", International Journal of Heat and Mass Transfer, Vol. 27, No. 10, pp. 1771$1779,1984$.

33. H. M. Badr, "Forced convection from a straight elliptical tube", Heat and Mass Transfer, Vol. 34, pp. 229-236, 1998.

34. A. Blaszczuk, M. Pogorzelec and T. Shimizu "Heat transfer characteristics in a largescale bubbling fluidized bed with immersed horizontal tube bundles", Energy, Vol. 162, pp. 10-19, 2018.

35. S.W. Kim and S.D. Kim, "Heat transfer characteristics in a pressurized fluidized bed of fine particles with immersed horizontal tube bundle", International Journal of Heat and Mass Transfer, Vol. 64, pp. 269-277, 2013.

36. S. E. Olsson, A.E. Almstedt," Local instantaneous and time-averaged heat transfer in a pressurized fluidized bed with horizontal tubes: influence of pressure, fluidization velocity and tube-bank geometry" Chemical Engineering Science, Vol. 50, No. 20, PP: 3231-3245, 1995.

37. R. K. Bansal, "Heat transfer studies from single cylinder and tube bundle in fluidized bed", Ph. D. Thesis, Mechanical Engineering, Faculty of the division of graduate studies, Georgia institute of technology, March, 1978.

38. N. Masoumifard, N. Mostoufi, A. A. Hamidi and R. Sotudeh-Gharebagh, "Investigation of heat transfer between a horizontal tube and gas-solid fluidized bed" International Journal of Heat and Fluid Flow, Vol. 29, No. 5, pp. 1504-1511, 2008.

39. M. M. Burr, "Investigation of instantaneous hydrodynamics and heat transfer to a horizontal tube immersed in a high-temperature gas-solid fluidized bed of large particles", Ph. D. Thesis, Oregon State University, June, 1998.

40. A. P. Baskakov and B. V. Berg, "Heat transfer between a fluidized bed and immersed cylinder", Inzhenerno-Fizicheskii Zhurnal, Vol. 10, No. 6, PP: 738-743, Sverdlovsk, 1966.

41. Y. Nagahashi, D. Yamamoto, J. R. Grace, and Y. Asako, "Forces on horizontal tubes of non-circular cross-section in fluidized beds", The 14th International Conference on Fluidization - From Fundamentals to Products", J.A.M. Kuipers, Eindhoven University of Technology R.F. Mudde, Delft University of Technology J.R. van Ommen, Delft University of Technology N.G. Deen, Eindhoven University of Technology Eds, ECI Symposium Series, 2013.

42. M. Abdrabboh, R. Sakr, M. A. Mohammad, and M. Mandour, "Experimental Investigation of Heat Transfer from Elliptic Tube Immersed in a Fluidized Bed." ASME. J. Thermal Sci. Eng. Appl. doi: https://doi.org/10.1115/1.4046318 (Accepted and being published Online via ASME), February 12, 2020.

43. Moffat, R. J., "Describing the uncertainties in experimental results," Experimental Thermal and Fluid Science, Vol.1, PP: 3-17, 1988.

44. Y. A. Cengel, "Heat transfer: A practical approach", second ed., McGraw-Hill, New York, 2003.

45. X. Tian, J. Yang, Z. Guo, Q. Wang and B. Sunden, "Numerical study of heat transfer in gravity-driven dense particle flow around a hexagonal tube", Powder Technology, 
Vol. 367, PP: 285-295, 2020.

\section{NOMENCLATURE}

$\mathrm{A}_{\mathrm{c}} \quad$ Cross-sectional area of heated cylinder, $\mathrm{m}^{2}$.

A Length of major axis, $m$.

B Length of minor axis, $m$.

$\mathrm{Cp}_{\mathrm{a}} \quad$ Specific heat of air, $\mathrm{J} / \mathrm{kg} \mathrm{K}$.

$\mathrm{D}_{\mathrm{h}} \quad$ Hydraulic diameter, $\mathrm{m}$.

$\mathrm{d}_{\mathrm{p}} \quad$ Particle's diameter, $\mathrm{m}$.

$\mathrm{G} \quad$ Acceleration due to gravity, $\mathrm{m} / \mathrm{s}^{2}$.

$\mathrm{H}_{\text {st }} \quad$ Static height of the bed, $\mathrm{m}$.

h Coefficient of average heat transfer, $\mathrm{W} / \mathrm{m}^{2} .{ }^{\circ} \mathrm{C}$.

$\mathrm{h}_{\theta} \quad$ Coefficient of local heat transfer, $\mathrm{W} / \mathrm{m}^{2} .{ }^{\circ} \mathrm{C}$.

$\mathrm{k}_{\mathrm{a}} \quad$ Thermal conductivity of air, W/m.K.

L Heated tube length, $\mathrm{m}$.

P The perimeter of the tested cylinder, $\mathrm{m}$.

Q Total input power to the heater, W.

$\mathrm{T}_{\mathrm{s}, \theta} \quad$ Local surface temperature of the body, ${ }^{\circ} \mathrm{C}$.

$\mathrm{T}_{\mathrm{b}} \quad$ Mean bed temperature, ${ }^{\circ} \mathrm{C}$.

$\mathrm{U}_{\mathrm{mf}}$ Minimum fluidization velocity, $\mathrm{m} / \mathrm{s}$.

$\mathrm{U}_{\text {sup }}$ Superficial air velocity, $\mathrm{m} / \mathrm{s}$.

\section{GREEK LETTERS}

$\mu_{\mathrm{a}} \quad$ Air dynamic viscosity, $\mathrm{kg} / \mathrm{m}$.s.

$\rho_{\mathrm{a}} \quad$ Air density, $\mathrm{kg} / \mathrm{m}^{3}$.

$\rho_{p} \quad$ Particle's density, $\mathrm{kg} / \mathrm{m}^{3}$.

$\Delta \mathrm{P} \quad$ Pressure drops across the fluidized bed, pascal.

E Volume fraction.

\section{DIMENSIONLESS GROUP}

Ar Archimedes number.

$\mathrm{N}_{\mathrm{u}} \quad$ Average Nusselt number.

$\mathrm{Nu}_{\theta} \quad$ Local Nusselt number.

Re Reynolds number.

Pr Prandtl number.

\section{SUBSCRIPTS}

$\Theta \quad$ Circumferential angle on tube surface.
A Air.
B Bed.
C Cylinder's cross-section.
P Particles 